\title{
SCENARIOS IN AN \\ ORGANIZATIONAL PERSPECTIVE
}

Henk A. Becker and Joseph W. M. van Doorn

In everyday life there are many kinds of scenarios-those embracing society as a whole, and those limited to the local community centre. There is considerable variation in scenario subject matter, range, level and degree of detail. ${ }^{1}$ Why have scenarios become so popular and which organizational arrangements have becn creatcd to design and implement this kind of policy-oriented futures research? This article looks at both elements of this question. It examines policy-oriented futures research in general, and scenarios as part of this type of research. It then discusses organizational structures for designing and applying scenarios. Following this, the strong and weak points of scenarios in policy formulation are explored and a number of conclusions are drawn.

IN THE MID-1970s Shell Corporation was dissatisfied with traditional forecasting. ${ }^{2}$ Nobody had predicted the 1973 oil crisis. When the oil crisis was at its height, forecasters predicted a long-term structural shortage of crude oil-this did not materialize. Shell no longer relies on predictions, except for issues such as demographic developments in the next five to 10 years.

Instead of traditional forecasts Shell uses scenarios to prepare its corporate strategy. A number of contextual scenarios are designed, describing possible future states of society that will confront Shell. Next, a number of strategies are developed. The impact of the contextual scenarios on each of the strategies, and the impact of the strategies on the corporate goals are then simulated. The next stage involves adapting the strategies so that they fit more closely with the contextual scenarios. This sequence of steps is repeated until the strategy formation has acquired the degree of sophistication management requires. In this approach, a scenario is a combination of a specific context and a specific strategy.

Shell has a department responsible for corporate planning. This department

Henk A. Becker is Professor of Sociology at Utrecht University, The Netherlands. Joseph W. M. van Doorn is Planning and Research Director, PMSvW/Young and Rubican Advertising Agency, Amsterdam, The Netherlands. 
prepares the exercises, and goes through each step with the managers who will have to work in the future according to the strategies. The mangers acquire a feeling for the robustness of each of the strategies involved. If the contextual conditions change in a direction unfavourable to the company, they are prepared for switches from preferred strategies to less favourable options and maybe even to emergency plans. The organizational unit responsible for this type of corporate planning must have a position in the organization as a whole that gives it a fair chance to participate in all stages of the policy-formation process.

\section{Policy-oriented futures research}

Since the mid-1970s policy-oriented futures research has developed into a growth industry. Traditional forecasting has prospered in a number of fields characterized by robust developments, for example the search for demographic trends. ${ }^{3}$ In fields with less hard data, the types of futures research which have gained in importance are those that help policy makers to cope with risk and uncertainty, the choice between alternative options and the requirements of negotiations. In the field of technological innovation, for example, technology assessment and related kinds of impact assessment are increasingly in demand. ${ }^{4}$ There are several reasons why policy makers have turned to futures research. They want to be informed about future developments in the context in which they are working. Secondly, futures research has become important for successful negotiations. A policy maker either uses the results of a futures research project to beat his opponents, or his opponents attack him by using futures research and he needs to have this kind of research available to hit back.

In order to provide insights into the challenges of the future and to provide weapons for the struggle for survival, policy-oriented futures research has to meet three requirements:

- It must be part of the processes of policy preparation, decision making and policy implementation, thus providing a continuous preoccupation with the future. Each stage will demand specific kinds of futures research.

- Futures studies must transform uncertainty into risk as much as possible ${ }^{5}$ The dynamics and complexity of the social systems which the policy maker wants to control demand analytical instruments that are able to consider the relative (un)predictability of the developments involved.

- Futures studies must elucidate the options open to the policy maker. Quicker than his competitors the policy maker needs to obtain an overview of the main paths open to him and of the consequences of following each of these paths.

Because in most instances policy makers are confronted with developments that can only be predicted in a restricted sense and that demand a choice between options, projects to generate and test scenarios have become a familiar phenomenon in many sectors of society. The national railway corporation in The Netherlands provides an example from the commercial sector. This corporation had to choose between alternative patterns of public rail transport in the coming decades. Because an increase in commuter transport was expected, a scenario 
was chosen that included the use of double-decker trains for short journeys.

In the non-profit sector the increase in policy-oriented futures research has been more visible, because private firms are less inclined to publish their experiences with policy formation. In the public health sector, for example, in 1979 the World Health Organization (WHO) launched a programme called "Health for all by the year 2000". Instruments to meet this ambitious target are health management, health planning and health education. To strengthen policy formation by member countries and by WHO itself, it was decided to utilize scenarios. 'I'hree countries have volunteered to provide pilot projectsFinland, Sweden and The Netherlands. The first contribution by The Netherlands was a project on scenarios for the elderly and their health. ${ }^{6}$ In the two years since the publication of the report, two government documents have been based partly on the results of this scenario project, and Amsterdam has started a scenario report on its resident elderly, taking the national project as a model. The scenarios on the elderly were designed by a committee of medical experts in cooperation with a research team provided by the Research Group on Planning and Policy Making of Utrecht University.

The Shell scenarios are produced by a planning unit that is located within the corporation. The scenarios on the elderly and their health were designed and tested by experts external to WHO and to the Dutch government's Department of Welfare, Public Health and Culture. The advantages and disadvantages of both alternatives will be discussed below.

\section{Organizational settings for scenario projects}

\section{Internal organizational settings}

Which conditions make it worthwhile to consider the alternative of internal organizational settings for scenario projects? The organization must be large enough to be able to afford a unit for futures research. 'I'his means being able to pay for at least five to six futures researchers on a permanent basis. Sometimes a number of small organizations have enough in common to be able to cooperate and create a futures research unit to serve all of them.

An organization also needs a continuous flow of futures research projects, including scenarios, to make the existence of a futures research unit worthwhile. If there is only a sporadic demand for futures research, an internal unit would be alternately underutilized and overtaxed. A flow of relatively homogeneous subjects is required, as a large diversity of subjects makes it impossible for the research unit to acquire specialized knowledge. An internal unit is to be preferred if the organization has to keep its futures research secret-business enterprises, military organizations, police forces, trade unions, for instance. Internal units, however, are only adequate if intellectual inbreeding can be avoided. For instance, a multinational corporation with branches in many countries will be able to assemble futures research task forces consisting of a sufficient diversity of members and participants who move from one project to another.

Often an organization only meets some of these requirements. In that case, an internal unit is often created together with provision in an annual budget to commission scenario projects from external research institutes or freelance 
scientists. In this case the futures research unit will be responsible for supervising the external projects.

Internal units for futures research are in a relatively strong position to cooperate with policy makers during all stages of the policy-making process. According to Stafford Beer, for example, futures exploration within an organization can only develop if the organization's subsystems are mutually supportive. ${ }^{7}$ Beer states that in most organizations an autonomous subsystem aimed at futures reconnaissance either does not exist or is ineffective because it is not connected to the flow of information from which policy decisions emanate, or is absorbed by the pressure of daily urgencies as part of a management system directed at practical operations. This observation has also been made by Van Gunsteren. ${ }^{8}$

At which management level should the futures research unit be situated? According to Cauwenbergh and Robaeys the three levels of management (top, middle and lower management) are to be regarded as subsystems influencing each other. ${ }^{9}$ Each subsystem is characterized by its own collection of specific thought and action patterns. Roughly speaking, top management is occupied with general strategic problems concerning the organization and its environment - it provides the ideas. Lower management also initiates, but within the limits of its technical-rational framework-it provides the facts. Constant strain exists between ideas and facts. This strain can be reduced through the coordinating and integrating role of middle management.

The specific patterns of thinking and acting of these three management levels result in requirements for the organizational setting of the futures research unit, as studies by King and Cleland, Ringbakk and Dawson, and Klingler indicate. ${ }^{10}$ Because of the strained relationship between the long-term planning activities of top-level management (including scenarios) and the short-term activities of lower-level management, it is vitally important that lower management actively participate in the preparation and implementation of long-term planning. Most planning departments are located too close to the top of the organization. This means that scenarios often emerge which are beautifully prepared, but which lack support from lower management. Scenario design needs to be part of a strategic planning process, with top, middle and lower management levels in turn being involved in producing ideas, scrutinizing them and turning them into general strategy and operational instructions.

These requirements apply to industrial enterprises, commercial firms in the service industries, non-profit organizations like trade unions, and the knowledge industry. In 1985 Utrecht University (one of the larger higher education institutions in The Netherlands, with 22000 students) embarked on a two-year project of strategic planning, taking the year 2001 as a time horizon. Task forces were assembled to deal with the future of about 20 aspects of the institution. Each task force invited 30 or more individuals from grassroot level (professors, students, administrative personnel), lower management (coordinators of research groups), middle management (boards of departments) and top management (board of the university) to participate in a Delphi project which included the drafting of contextual scenarios and strategies, and to write essays and participate in workshops. Evidently, strategic planning in universities requires an approach that is both top-down and bottom-up. 


\section{External organizational setting}

External organizational setting of futures research units (including scenario projects) is a preferable solution if the organization is too small to house a unit of its own. External projects are also required if a discontinuous flow of projects is involved. In this case external research institutes can be contracted each time a new project has to be dealt with. Heterogeneous projects make external researchers a relevant alternative, because for each project a specialized research unit or freelance researcher can be contracted. External contracts will also be preferred if secrecy is not too important, for instance if policy formation in public administration is aimed at. If the aim is for public participation in strategic planning, external contracts are adequate-innovation in health policy, for example, can be organized as a process of strategic planning involving large numbers of individuals, and hospital boards and similar groups. External futures research can provide a safeguard against intellectual inbreeding if participants move from one project to another often enough.

External futures research projects can be combined with internal projects. The organization could also opt for an internal unit whose role is to supervise research contracts and to stimulate application of the results, without doing futures research itself. A construct of this kind has a severe drawback, however, in that research experts in a supervising unit quickly lose touch with futures research itself. The supervision and implementation unit within an organization should be placed close to both top and bottom management levels, ie, in middle or lower top management.

\section{Strong points of scenario projects}

Why do organizations bother to obtain scenarios, either from futures research units of their own or by contracting outsiders? What are the advantages of this type of futures research?

\section{Learning}

In the first place, scenarios provide the organization with a learning environment for strategy formation and for monitoring the outcomes of strategic planning. The organization obtains an instrument to simulate society as its future environment, and to simulate its own future and the outcomes of its own activities. This learning may take place without subjecting the organization's acknowledged set of rules to change. Double-loop learning (where the rules do change), or deutero learning (where the organization learns about its own learning process) may also take place. It does not matter whether this learning uses classical feedback mechanisms, or whether it is based on the principles of an instructive learning process, a selective learning process, or a mixture of both. ${ }^{11}$ What does matter, however, is that the authors and/or researchers are convinced that 'deciding on decisions', 'planning the planning' and arranging for adequate futures research should be made into learning processes. Strategic management encourages the learning-process approach through double-loop learning and makes it a suitable breeding-ground for futures research as advocated in this article. ${ }^{12}$ 


\section{Interactive planning}

Scenario projects are strong in providing opportunities for interacting planning. As Ackoff explains, interactive planning can tell corporations:

- how to formulate the system of problems and opportunities that they face;

- how to formulate goals, objectives and ideals and how to select and evaluate the means by which they should be pursued;

- how to determine what resources will be required and how they should be acquired or developed; and

- how to implement and control planning decisions and the planning process itself.

Ackoff gives examples of reference scenarios (we call them 'contextual scenarios'), and states that their purpose is to reveal the implications of a corporation's current behaviour and assumptions. He also gives examples of "idealized designs", which provide guiding images for the corporation and ways and means of putting these designs into practice. ${ }^{13}$

\section{Analysis of competitors}

Thirdly, scenario projects can assist corporations and other collective actors to find out what others in their field of activities might do in the future. In this sense, Porter provides techniques for analysing industries and their competitors. ${ }^{14}$ Pfeffer and Salancik explain how organizational environments affect and constrain organizations and how organizations respond to external constraints. They also provide a guide to designing and managing organizations that are externally constrained..$^{15}$

\section{Successful examples}

Finally, there are enough examples of the high impact of the outcomes of scenario projects and of adequate settings for futures research units (Shell for instance), to make it possible to advocate the utilization of scenarios in strategic management in a convincing way.

\section{Weak points of scenario projects}

We should also examine scenarios to establish which aspects of scenario projects are in need of improvement.

\section{Communication}

In the first place we come across a problem of communication. Scenario researchers have not yet developed and tested a language for communicating adequately with those who use the results of their projects. Concepts like risk and uncertainty are still relatively unknown. Managing an organization in an environment that becomes increasingly uncertain, for instance, requires approaches which, although available in scenario methodology, are little utilized. The credibility of futures researchers is related to this communication problem. Makridakis for instance found that, "Although technical competence (or even excellence) is attributed to the preparers by the users, the confidence of 
the users in the ability of the preparers to choose the best technique is relatively low." 16

\section{Evaluation}

Secondly, the evaluation of old scenario projects is still in its infancy. Futures research, like scenario projects, progresses by learning from its own past. Ascher provides an ex post facto evaluation of forecasts in six major areas. ${ }^{17}$ Ex post facto evaluation of scenario projects will require much attention in years to come.

\section{Project scale}

In the third place, scenario methodology is too often directed at large projects which demand more than one man- or woman-year. Methodology has to be developed and tested that provides guidelines for instant scenario projects (up to one man-week) and mini scenario projects (between one man-week and one man-year). If adequate baseline data are available and if the scenario team is experienced, small-scale projects can be carried out quickly and at low cost. Policy making often requires short-term projects. On the other hand, for instance in developing countries, resources are only available for small-scale projects.

\section{Complexity and simplicity}

Scenario projects can be designed to produce either complex or simple results. Research into the utilization of social science has shown that policy makers have a preference for the use of simple techniques. In Balanchandra's study as well as in studies by Töpfer, McHale, and Eppink et al, techniques like brainstorming, trend extrapolation and generation of expert opinions score highest. ${ }^{18}$ The study by van Doorn and van Vught is evidently an exception to this rule. ${ }^{19}$ Wheelwright and Makridakis found that the degree of complexity of a technique was the most important reason for ceasing to use that technique. ${ }^{20}$

When we apply these findings to scenario projects, two contrary developments are possible for the future. Firstly, policy makers could reject the scenario method because of its complexity and the relative difficulty of handling the results of scenario projects. This would depend, however, not only on the preferences of a specific policy maker, but also on the overall situation in a policy arena, and whether or not scenarios are utilized. Secondly, there could be an increase in the utilization of scenarios. In this case it is of the utmost importance that methodology is developed for small-scale, less time-consuming scenario projects. Of similar importance is the elaboration and testing of techniques for improving communication between scenario experts and policy makers. ${ }^{21}$

\section{Perspectives}

Nothing breeds success like success. Since the mid-1970s a considerable number of international organizations (OECD, WHO, etc), government agencies, business corporations (eg, Shell) and private non-profit organizations have utilized scenarios for their own benefit. Their insight into their own future and their position in negotiations have profited from these applications. Under these circumstances it is reasonable to expect utilization of this type of policy- 
oriented futures research to increase. One aspect of this development is the organizational setting of this kind of research. We have summarized a number of experiences of providing organizational solutions, both within and outside the organization itself, but innovations with regard to organizational solutions will continue. We round off by presenting a recent test case in The Netherlands that led to promising results.

Early in 1986, the Dutch House of Parliament had to decide on a bill implying drastic revisions of the social security system. A highly complicated set of data was involved. This induced a team of sociologists and social economists from the Research Group on Planning and Policy Making of Utrecht University, economists from labour unions and representatives from organizations of people receiving social security benefits to inaugurate a 'critical centre'. A number of rooms were rented in the Hotel Corona, near the House of Parliament. Personal computers were fed with statistical information and a model representing the social security system and its impacts. Qualitative information was also kept ready. All persons involved, Members of Parliament as well as journalists and government officials, were then invited to put questions to the team. Amendments to the bill considered by members of the parliamentary opposition, for instance, were analysed by the "Corona Group" with regard to their potential impacts. This direct way of cooperation between the corridors of power and the applied science of academic institutions has been productive. Practical information based on scientific insights has been disseminated, and Francis Bacon's statement that "science is power" has been demonstrated once again. Furthermore, a new solution to the problem of finding an adequate organizational setting for scenarios and similar kinds of policy-oriented futures research has been designed and tested.

\section{Notes and references}

1. To mention a few: Interfutures Project, "Facing the future" (Paris, OECD, 1979); IIASA Energy Scenario (Laxemburg, 1981); L. C. Thurow, The Zero-sum-Society (New York, Basic Books, 1980).

2. See P. W. Beck, "Forecasts: opiates for decision makers", paper presented to the Third International Symposium on Forecasting, 1983, Philadelphia.

3. N. Keilman, "The unpredictability of population trends", in H. A. Becker and A. L. Porter (editors), Methods and Experiences in Impact Assessment (Dordrecht, Reidel, 1986).

4. H. A. Becker and A. L. Porter (editors), Impact Assessment Today (Utrecht, Van Arkel, 1986).

5. On risk and uncertainty see for instance: E. J. Mishan, Cost-Benefit Analysis (London, George Allen and Unwin, 1979); A. K. Dasgupta and D. W. Pearce, Cost-Benefit Analysis (London, Macmillan, 1978).

6. C. F. Hollander and H. A. Becker (editors), Growing Old in the Future (Dordrecht, Martinus Nijhoff, 1985).

7. S. Beer, The Brain of the Firm (London, Penguin Press, 1972); idem, Platform for Change (London, John Wiley, 1975); idem, The Heart of the Enterprise (New York, Wiley, 1975).

8. H. R. van Gunsteren, "Instructie en Selectie: over de verwerking van toekomststudies door overheidsorgaisaties" ("Instruction and selection: the implementation of futures studies by governmental bodies"), in Toekomstdenken en het Openbaar Bestuur ("Futures Research and Public Administration") (The Hague, Staatsuitgeverij, 1982).

9. A. van Cauwenbergh and N. A. A. van Robaeys, Strategisch gedrag ("Strategic behaviour of organizations") (Deventer, Kluwer, 1978).

10. W. R. King and D. I. Cleland, Strategic Planning and Policy (New York, Van Nostrand Rheinhold Company, 1978); K. A. Ringbakk and R. W. Dawson, "Organized planning in 
40 major US corporations", Report, Stanford Research Institute, Berkeley, 1968; J. S. Klingen, Strategische Manoeuvreerbaarheid en Strategische Besturing ("Strategic operating and management') (Alphan aan den Rijn, Somsom, 1973).

11. C. Argyris and Donald Schon, Organizational Learning: A Theory of Action Perspective (Amsterdam, Addison-Wesley, 1978); H. R. van Gunsteren, op cit, reference 8.

12. H. I. Ansoff, R. P. Declerck and R. L. Hayes (editors), From Strategic Planning to Strategic Management (London, John Wiley, 1976).

13. R. A. Ackoff, Creating the Corporate Future: Plan or Be Planned For (New York, Wiley, 1981).

14. M. E. Porter, Competitive Strategy: Techniques for Analyzing Industries and Competitors (New York, The Free Press, 1980).

15. J. Pfeffer and G. R. Salancik, The External Control of Organizations: A Resource Dependence Perspective (New York, Harper and Row, 1978).

16. S. Makridakis, S. Wheelwright and V. McGee, Forecasting Methods and Applications (New York, Wiley, 1983).

17. W. Ascher, Forecasting, A Reappraisal (Baltimore, John Hopkins University Press, 1978).

18. R. Balanchandra, "Perceived usefulness of technological forecasting techniques", Technological Forecasting and Social Change, 16, 1980, pages 155-166; A. Töpfer, "Corporate planning and control in German industry", Long Range Planning, February 1978; J. McHale, "The changing pattern of futures research in the USA", Futures, 5, (3); D. J. Eppingk, D. Keuning and K. de Jong, "Corporate planning in The Netherlands", Long Range Planning, October 1976.

19. J. W. M. van Doorn and F. A. van Vught, "Futures research in The Netherlands 19601980', Futures, 15, (6), December 1983.

20. S. Makridakis and S. Wheelwright, "Forecasting-framework and overview", in S. Makridakis and S. Wheelwright (editors), Forecasting Studies in the Management Sciences, 12 (1979, Amsterdam, North-Holland).

21. H. A. Becker, "Handling futures research" (Proceedings of the 1987 conference of the International Association for Impact Assessment, Barbados) publication not foreseen before the end of 1988. 